\title{
Epidemiological, Clinical, Therapeutic and Prognostic Aspects of Puerperal Infections within the Gynecology Obstetrics Department of Yalgado Ouedraogo University Teaching Hospital (CHU-YO), Burkina Faso
}

\author{
Kain Dantola Paul1, Zamané Hyacinthe ${ }^{2}$, Ouédraogo Issa ${ }^{3}$, Ilboudo Isabelle ${ }^{2}$, \\ Millogo/Traore Françoise², Ouédraogo Ali1 ${ }^{1}$ Bonané/Thiéba Blandine ${ }^{2}$ \\ ${ }^{1}$ Teaching Hospital of Tengandogo, Ouagadougou, Burkina Faso \\ ${ }^{2}$ Yalgado Ouedraogo Teaching Hospital, Ouagadougou, Burkina Faso \\ ${ }^{3}$ Regional Teaching Hospital of Ouahigouya, Ouahigouya, Burkina Faso \\ Email: zanlotoma@yahoo.fr
}

How to cite this paper: Paul, K.D., Hyacinthe, Z., Issa, O., Isabelle, I., Françoise, M., Ali, O. and Blandine, T. (2021) Epidemiological, Clinical, Therapeutic and Prognostic Aspects of Puerperal Infections within the Gynecology Obstetrics Department of Yalgado Ouedraogo University Teaching Hospital (CHU-YO), Burkina Faso. Open Journal of Obstetrics and Gynecology, 11, 1657-1664.

https://doi.org/10.4236/ojog.2021.1112155

Received: November 7, 2021

Accepted: December 11, 2021

Published: December 14, 202

Copyright $\odot 2021$ by author(s) and Scientific Research Publishing Inc. This work is licensed under the Creative Commons Attribution International License (CC BY 4.0).

http://creativecommons.org/licenses/by/4.0/

\begin{abstract}
Objective: Conduct a study about the epidemiological, clinical, therapeutic and prognostic aspects of puerperal infections within Gynecology Obstetrics department of CHU-YO during the study period. Patients and Methods: This was a cross-sectional and descriptive study. The study period was from January $1^{\text {st }}$ to December $31^{\text {st }}, 2019$. Data collection was retrospective. The exhaustive sample included all female patients having a puerperal infection. Results: Our study included 65 patients. The frequency of puerperal infections represented $1 \%$ of deliveries, the average age of patients was $27 \pm 7.26$ years. Housewives represented $64.4 \%$ of the patients. Hyperthermia and abdominal-pelvic pain respectively occurred in $63.8 \%$ and $21.3 \%$ of patients. The patients had given birth by caesarean section in $83.1 \%$ of cases. Endometritis represented $76.9 \%$ of cases of puerperal infections. The patients were treated with antibiotics, uterotonics and symptomatic therapy. Maternal death occurred in $13.9 \%$ of cases. Conclusion: A focus should be put on preventive measures in front of any high-risk puerperal infection situation.
\end{abstract}

\section{Keywords}

Puerperal Infection, Endometritis, CHU-YO

\section{Introduction}

According to many sources, puerperal infection is the second leading cause of 
maternal mortality and morbidity worldwide. These infections were one of the most common causes of death and disability in the postnatal period. In addition, they are quite common in the world in general and even more in developing countries [1] [2].

In Africa, infections were the third leading cause of maternal death and the second leading cause of early neonatal death. In addition, they were the first leading cause of postoperative morbidity in 2011 [3]. The advent of antibiotics and the promotion of aseptic measures enabled to reduce their incidence within developed countries. The incidence is still high in developing countries, ranging from $15 \%$ to $25 \%$ depending on the socio-economic context [4] [5].

In Burkina Faso, infections were responsible for $7.4 \%$ and $12 \%$ of maternal deaths in 2008 and 2009 respectively at the Yalgado Ouédraogo Teaching Hospital [6]. In Burkina Faso, puerperal infections are still responsible for $15 \%$ of maternal deaths despite the efforts made by the health system to improve access to obstetrical care [7] [8]. This raises the question of the effectiveness of probabilistic antibiotic treatments because of the low national coverage of laboratories and qualified personnel for the identification and sensitiveness of the responsible germs before starting any treatment.

Puerperal infections are therefore a frequent reason for consultation or extension of women's hospitalization in our hospitals. Hence the need is to conduct this study on puerperal infections in order to specify the epidemiological, diagnostic, therapeutic and prognostic aspects for better treatment.

\section{Patients and Methods}

Our study took place in the Gynecology-Obstetrics department of Yalgado Ouédraogo Teaching Hospital in Ouagadougou, Burkina Faso. It was a crosssectional and descriptive study. The study period ranged from January $1^{\text {st }}$ to December $31^{\text {st }}, 2019$. Data collection method was retrospective. Our study included all hospitalized patients who were in the postpartum period during the study period. The target population was patients hospitalized for puerperal infections. We defined a puerperal infection as any infection originating from the placental insertion site. Data sources were patient records, hospitalization registers, operative report registers, referral and evacuation forms. The collect of data were done using a questionnaire pre-tested. It included patient identity, clinical characteristics, paraclinical, therapeutics and prognosis aspects. The data were collected and analysis using epi-info software 7.2.1.0. version 2010 Word and Excel. The results were presented in percentage for qualitative variables and in means standard deviation for quantitative variables.

Ethics Approval: This study was conducted under the supervision of the university JOSEPH KI-ZERBO of Ouagadougou, medical school. We obtained the approval of the Medical Establishment Commission of Yalgado OUEDRAOGO Teaching Hospital which acts as an ethics committee at the local level. Confidentiality of individual data was ensured at all stages of the study, during the 
collection and analysis of data through the use of individual and anonymous data collection forms.

\section{Results}

\subsection{Frequency}

During the study period, the maternity ward of the Yalgado Ouédraogo Teaching Hospital recorded 6413 deliveries; we identified 65 cases of puerperal infections, representing $1 \%$ of deliveries.

\subsection{Sociodemographic Characteristics of Patients}

The average age of the patients was $26.7 \pm 7.26$ years with extremes of 16 and 46 years. Housewives accounted for $64.4 \%$ while patients living in rural areas represented $38 \%$. As for primiparous women, they represented $38.3 \%$.

\subsection{Clinical Aspects}

The reasons for admission were hyperthermia (63.8\%), abdominal and pelvic pains $(21.3 \%)$, and metrorrhagia $(14.9 \%)(\mathrm{n}=47)$. Patients who went through cesarean section delivery represented $83.08 \%(n=65)$.

Table 1 shows the distribution of patients having gone through cesarean section according to the cesarean section indication.

Upon admission, $66.0 \%$ of patients had a high temperature (above $38.5^{\circ} \mathrm{C}$ ) while $47.1 \%$ of them $(n=34)$ were in good general condition. Fetid lochia represented $46.0 \%$ followed by foul-smelling lochia (54.1\%). The average hospitalization duration was 10 days with extremes of 5 and 27 days. 04 types of puerperal infections were identified at the end of the clinical examination. Endometritis was the predominant puerperal infections. Table 2 presents the distribution of patients according to the type of puerperal infection.

\subsection{Paraclinical Aspects}

Out of the 65 patients, lochiae was collected from 51 patients. Table 3 shows the

Table 1. Distribution of patients according to cesarean section indications.

\begin{tabular}{ccc}
\hline Indications & Number & Percentage \\
\hline Acute fetal distress & 13 & 31 \\
Breech presentation & 7 & 16.7 \\
Fetal-pelvic disproportion & 5 & 11.9 \\
Placenta prævia & 5 & 11.9 \\
Failure to engage at full dilatation & 4 & 9.5 \\
Fetal macrosomia & 4 & 9.5 \\
Generally narrowed pelvis & 3 & 7.1 \\
Shoulder presentation & 1 & 2.4 \\
Total & 42 & 100 \\
\hline
\end{tabular}


Table 2. Various types of puerperal infections.

\begin{tabular}{ccc}
\hline Types of puerperal infections & Number & Percentage (\%) \\
\hline Endometritis & 50 & 76.9 \\
Pelviperitonitis & 3 & 4.6 \\
Septicemia & 9 & 13.8 \\
Acute generalized peritonitis & 3 & 4.6 \\
Total & 65 & 100.0 \\
\hline
\end{tabular}

Table 3. Distribution of germs identified in lochia sampling.

\begin{tabular}{ccc}
\hline Germs & Number & Percentage \\
\hline Escherichia coli & 21 & 41.1 \\
Staphylococcus aureus & 10 & 20.3 \\
Streptococcus agalactiae & 8 & 15.4 \\
Klebsiella pneumoniae & 6 & 11.3 \\
Staphylococcus épidermidis & 4 & 7.5 \\
Streptococcus pyogenes & 1 & 2.2 \\
Others & 1 & 2.2 \\
Total & 51 & 100 \\
\hline
\end{tabular}

distribution of the identified germs.

Escherichia coli accounted for $41.1 \%$ of the identified germs.

\subsection{Therapeutic Aspects}

The majority of patients received treatment based on antipyretics, antibiotic therapy each representing $89.2 \%$, and then analgesics $87.7 \%(n=65)$.

\subsection{Prognosis Aspects}

The percentage of maternal death was $15.4 \%$. Patients who died of sepsis represented $77.8 \%$ againts $22.2 \%$ of those dead by hemorrhagic shock. Newborns who died during the study period accounted for $1.5 \%$.

\section{Discussion}

Limitations and Constraints: This study was conducted in the Gynecology-Obstetrics department of Yalgado Ouédraogo Teaching Hospital. The fact that it is retrospective study has leaded to limitations by:

- The loss of some of clinical folders;

- The insufficiency of information in some of clinical folders;

- The non-full complete information of important items in some of clinical folder like level of education, the data of anthropometric parameters.

$\checkmark$ In our series, the frequency of puerperal infections was $1 \%$, a rate below those found by Ngonzi [9] in Uganda and Saizonou [10] in Benin, which were re- 
spectively $2 \%$ and $5.9 \%$. We found a rate of $2.3 \%$ of puerperal infections for caesarean deliveries against $1.8 \%$ of puerperal infections for vaginal deliveries. These frequencies corroborate Malavaud's works [11] in Toulouse, who found a rate of $1.9 \%$ for vaginal deliveries and $5.8 \%$ for caesarean sections through a study based on a systematic and standardized collection of data relating to new infection cases among women having delivered over a threemonths period in 2003. The frequency of puerperal infections in sub-Saharan Africa varies from one country to the other. This could be explained by differences as regards the definition and diagnostic criteria monitoring of puerperal infections. Besides, the incidence of puerperal infections varies depending on the population studied and health practices.

$\checkmark$ The average age of the patients was 26.7 years with extremes of 16 years and 46 years. This average age is close to that found by Ngonzi [9] in Uganda in 2018 which was 25 years, also close to that found by Ouédraogo et al in Burkina Faso in 2014 which was 25.2 years [12]. Patients under 35 years were the most represented with a rate of $85.2 \%$. Saizonou [10] in Benin in 2010 reported a predominance of the same age group with a rate of $88.2 \%$. This predominance of the young age group is due to the fact that this group is sexually active. Furthermore, young maternal age has been described as a factor associated with puerperal infections in the literature [13]. Housewives represented the majority with a rate of $64.4 \%$. This frequency is close to that found by Ouédraogo et al. in Burkina Faso in 2014 estimated at 62.7\% [12]. This predominance of housewives in our study could be explained by their unfavorable socioeconomic conditions. Several studies have shown that low socioeconomic level is a risk factor for puerperal infections [14].

$\checkmark$ In our study series, patients admitted for hyperthermia accounted for $63.8 \%$, abdomino-pelvic pains represented $21.3 \%$ and $14.9 \%$ for metrorrhagia. These rates are below those found by Ouédraogo [12] in the same department, which were respectively $98 \%, 77.4 \%$ and $55.8 \%$. These differences could be explained by the fact that Ouédraogo was only interested in endometritis and to the type of study which was prospective.

$\checkmark$ In our series, caesarian sections accounted for $83.08 \%$. The literature has established the link between caesarian section and puerperal infection. Axelsson [15] conducted a study stating that cesarean section was associated with the occurrence of postpartum endometritis. Another study conducted by Leth [16] showed that caesarian section was associated with the occurrence of bacteremia, surgical site infection and postpartum endometritis. The reduction of infectious complications induced by cesarean sections is based on the control of the cesarean sections rate, the use of antibiotic prophylaxis, and the reduction of numerous factors involved in the infection risk such as the reduction of the preoperative stay duration, parietal disinfection performed just before the procedure, and preoperative preparation of the surgical field. Escherichia coli, Staphylococcus aureus and Streptococcus agalactiae were 
respectively the 3 main germs identified. Our results are similar to those found by KANE GUEYE [17] at Le Dantec in Dakar, who found respectively $39 \%$ of Escherichia coli and 19\% of Staphylococcus.

$\checkmark$ Treatments based on analgesics and antipyretics were administered according to the clinical symptoms. Antibiotic therapy is the therapeutic arsenal for any infection treatment. In our series, the use of antipyretics, analgesics and antibiotics respectively accounted for $89 \%, 87.7 \%$, and $89.2 \%$. These rates are below those found by Ouédraogo et al. [12] which were respectively estimated at $96.1 \%$; $96.1 \%$; and $100 \%$. These differences could be explained by the selection of inclusion criteria and the type of study.

$\checkmark$ The average hospitalization stay was 10 days with extremes of 5 and 27 days. The case fatality related to puerperal infections was estimated at $13.9 \%$. Our result is close to that of Soma [18] in 2016 who found $14.9 \%$ and is below those of Sofo [19] and Kabré [20] who respectively found $25.2 \%$ and $20 \%$. The frequency of infections causing maternal deaths is higher in our developing countries than in developed countries due to strict aseptic measures. $17 \%$ of newborns died during the study period. This rate is close to that found by Owono Etoundi [21] (18.5\%) in Yaoundé in 2017. The high fetal mortality in our study testifies the severity of fetal damage in pregnancy complication cases. The serious complications observed and their consequences, call for the creation of obstetric intensive care units within busy maternity units. These results show the contribution of puerperal infections both on hospitalization duration and on maternal and neonatal mortality. Several reasons could explain the high lethality of puerperal infections, namely late diagnosis, lack of appropriate antibiotic therapy, and poor general condition of the patients at the time of diagnosis.

\section{Conclusion}

Hyperthermia was the important clinical aspect of puerperal infections. Escherichia coli accounted for $41.1 \%$ of the identified germs. Studies about the factors associated with the occurrence of these deaths among mothers developing infections in maternity wards are therefore needed.

\section{Conflicts of Interest}

The authors declare no conflicts of interest regarding the publication of this paper.

\section{References}

[1] Lamy, C., Zuily, S., Perdriolle, E., Gauchotte, E., Villeroy-de-Galhau, S., Delaporte, M.-O., et al. (2012) Management of Postpartum Infections. Journal of Gynecology Obstetrics and Human Reproduction, 41, 886-903.

https://doi.org/10.1016/j.jgyn.2012.09.024

[2] Quenti, R. and Verdon, R. (2012) Upper Genital Infections: Microbiological Bases for Diagnosis and Treatment. European Journal of Obstetrics \& Gynecology and Re- 
productive Biology, 41, 850-863. https://doi.org/10.1016/j.jgyn.2012.09.015

[3] Chaufreau, D. and Pittet, D.V. (2011) Special Session on Patient Safety and Control of Nosocomial Infections in Maternity Wards for the Achievement of Health Sector Related MDGs in Africa.

[4] World Health Organization (2004) Beyond the Numbers. Examining Maternal Deaths and Complications to Make Pregnancy Safer. World Health Organization, Geneva, $154 \mathrm{p}$.

[5] Thonneau, P., Fougeyrollas, B., Ducot, B., Boubilley, D., Dif, J., Lalande, M., et al. (1998) Complications of Abortion Performed under Local Anesthesia. European Journal of Obstetrics \& Gynecology and Reproductive Biology, 81, 59-63. https://doi.org/10.1016/S0301-2115(98)00147-X

[6] Ministry of Health (Burkina Faso) (2009) Statistical Yearbook of Yalgado Ouédraogo Teaching Hospital. 30.

[7] National Institute of Statistics and Demography (INSD), Burkina (2013) Annual Survey by Unified Questionnaire of Well-Being Basic Indicators 2007 (Online).

[8] Ministry of Health/DSF/Burkina-Faso 2012 (2012) Roadmap for the Reduction of Maternal and Neonatal Mortality. Review Document. 46.

[9] Ngonzi, J., Bebell, L.M., Fajardo, Y., Boatin, A.A., Siedner, M.J., Bassett, I.V., et al. (2018) Incidence of Postpartum Infection, Outcomes and Associated Risk Factors at Mbarara Regional Referral Hospital in Uganda. BMC Pregnancy and Childbirth, 18, 270. https://doi.org/10.1186/s12884-018-1891-1

[10] Saizonou, J., Ouédraogo, L., Paraiso, M.N., Ayélo, P., Kpozéhouen, A., Daraté, R. and Traoré, E. (2014) Epidemiology and Management of Per-Partum Infections in the Maternity Ward of the Teaching Departmental Hospital of Ouémé-Plateau in Benin. The Pan African Medical Journal, 17, 89. https://doi.org/10.11604/pamj.2014.17.89.2857

[11] Malavaud, S., Bou-Segonds, E., Berrebi, A., Castagno, R., Assouline, C. and Connan, L. (2003) Nosocomial Infections in Mother and Child: About an Incidence Survey of 804 Deliveries. Journal of Gynecology and Obstetrics and Reproductive Biology, 32, 169-174.

[12] Ouédraogo, C.M.R., Ouattara, A., Sana, A., Ouédraogo, A., Kain, D.P., Komboigo, E., et al. (2016) Obstetric Endometritis at the CHU-Yalgado Ouédraogo of Ouagadougou (Burkina Faso). About the Management of a Series of 102 Cases. Bulletin de la Société de Pathologie Exotique, 109, 334-339.

https://doi.org/10.1007/s13149-016-0514-1

[13] Chaim, W., Bashiri, A., Bar-David, J., Shoham-Vardi, I. and Mazor, M. (2000) Prevalence and Clinical Significance of Postpartum Endometritis and Wound Infection. Infectious Diseases in Obstetrics and Gynecology, 8, 77-82.

https://doi.org/10.1002/(SICI)1098-0997(2000)8:2<77::AID-IDOG3>3.0.CO;2-6

[14] Olsen, M.A., Butler, A.M., Willers, D.M., Gross, G.A., Devkota, P. and Fraser, V.J. (2010) Risk Factors for Endometritis after Low Transverse Cesarean Delivery. Infection Control \& Hospital Epidemiology, 31, 69-77. https://doi.org/10.1086/649018

[15] Axelsson, D., Brynhildsen, J. and Blomberg, M. (2018) Postpartum Infection in Relation to Maternal Characteristics, Obstetric Interventions and Complications. Journal of Perinatal Medicine, 46, 271-278. https://doi.org/10.1515/jpm-2016-0389

[16] Leth, R.A., Møller, J.K., Thomsen, R.W., Uldbjerg, N. and Nørgaard, M. (2009) Risk of Selected Postpartum Infections after Cesarean Section Compared with Vaginal Birth: A Five-Year Cohort Study of 32,468 Women. Acta Obstetricia et Gynecologica Scandinavica, 88, 976-983. https://doi.org/10.1080/00016340903147405 
[17] Kane Guye, S.M., Ba/Gueye, M., Siby/Diop, A., Faye, E.O., Boye, C.S., M’ Boup, S., Moreau, J.C. and Diadhiou, F. (2011) Per Partum Infection. Bacteriological Profile and Management Strategies at the Gynecological and Obstetrical Clinic of CHU Le Dantec de Dakar. Medecine d' Afrique Noire, 5810, 451-454.

[18] Soma, S. (2016) Maternal Mortality in the Department of Gynecology-Obstetrics of the CHU-YO of Ouagadougou: About 181 Cases Collected from Janvier1st, to 31st Décembre, 2016. Thesis in Medicine UFR/SDS University of Ouagadougou, Ouagadougou, No. 337, 115 p.

[19] Sofo, W.A.K. (2012) Maternal Mortality in the Gynecology and Obstetrics Department of the CHU YO of Ouagadougou; Epidemiological, Clinical and Evolutionary Aspects about 1159 Cases Collected from 2001 to 2010. Thesis in Medicine UFR/ SDS University of Ouagadougou, Ouagadougou, No. 115, 79.

[20] Kabré, K. (2014) Maternal Mortality in the Gynecology and Obstetrics Department of the CHU YO of Ouagadougou: Epidemiological, Clinical and Evolutionary Aspects: About 257 Cases Collated from 2011 to 2013. Thesis in Medicine UFR/SDS University of Ouagadougou, Ouagadougou, No. 109, 129.

[21] Owono Etoundi, P., Metogo Mbengono, A.J., Tchokam, L., Danwang, C., Kago Tcheyanou, L., Afane Ela, A. and Ze Minkandé, J. (2017) Obstetrical Complications Admitted to the Intensive Care Unit: Epidemiology, Diagnosis and Evolution of Obstetrical Complications in Two Intensive Care Units in Cameroon. Health Sciences and Disease, 18, 48-52. 